WHITE PAPER FOR PlANETARY AND ASTROBIOLOGY SCIENCE STRATEGY

\title{
Human Factors for Long Duration Space Missions
}

\author{
Janet Vertesi ${ }^{1}$ and Abigail Rymer ${ }^{2}$
}

${ }^{1}$ Princeton, ${ }^{2}$ Johns Hopkins APL

Corresponding author: Abigail.rymer@jhuapl.edu

This White Paper is extracted from the Neptune-Odyssey Planetary Mission Concept Study [Rymer et al., 2020] in order to provide the important points and references as a relatively brief stand alone White Paper.

Space exploration is a team effort, and missions require a plan for managing interactions over a multi-decade span. The literature on the science of team science provide a series of best practices and insights into the human element of scientific collaborations. We advocate that the Planetary community deliberately draw upon lessons learned from past missions, especially Cassini, to identify ways to meet three significant challenges on the human scale for a future outer solar system missions (e.g. Neptune, Pluto, Interstellar Probe) these aspects also apply to other missions and should be shared accordingly.

Data Stewardship. Prior studies of long-term projects demonstrate significant hurdles in data management, including establishing standards, maintaining compatibility, and instrumental health (Ribes, 2007; 2013). We advocate for the deliberate development (and fund) of techniques to:

- Produce robust, long-term plans for data stewardship, with clear expectations shared across the instrumentation suite (Bietz, 2009)

- Share data in ways consistent with the operational considerations of the mission (Vertesi, and Dourish, 2011)

- Produce a local database that feeds the archive pipeline with quick-view products available for establishing cross instrumental partnerships (Birnholtz, 2003).

- Fund stewardship, compatibility, and process responsibilities, making data work a valued part of the investigation ( Lee and Dourish, 2006).

Planning for the Long Term. From point of mission formulation through development and cruise, it will take well over a decade for this mission to reach its target, let alone to begin investigations. We advocate for the deliberate development (and fund) of techniques to:

- Adopt a bureaucratic-hierarchical form (Weber, 1968), consistent with the Flagship organizational style which best permits multi-generational leadership and team participation and turnover. Such social forms are more likely to support women and minorities in advancement (Freeman, 1972; Smith-Doerr, 2004) and to support the encyclopedic data collection expected of Flagship missions (Vertesi, in press).

- Include a plan for multi-generational leadership. For example, each instrument team could nurture more than one deputy-PI to develop to share the experience and skill set necessary for leadership (Linde, 2001).

International Partnership. Missions of this scale and scope benefit tremendously from international partners, both in terms of scientific expertise and fiscal support. For Neptune, for 
example, advanced discussions exist, e.g. Workshop on In Situ Exploration of the Ice Giants, Marseille, France, January 2019 and a just-completed ESA-led study (http://sci.esa.int/futuremissions-department/61307-cdf-study-report-ice-giants/ found that an ESA-provided entry probe is the most technologically mature and least expensive option for ESA participation in a NASAled Ice Giant mission. International partnerships can be difficult to sustain due to the pressures of institutional and national requirements as well as cultural differences (Sheehan, 2007). Study of the extraordinarily successful Cassini mission demonstrates this is best managed through relational work at the level of the mission scientists and technical teams (Groen, 2005), We advocate for the deliberate development (and funding) of techniques to manage this challenge.

Bietz, M.J., C. P. Lee, (2009). in Proceedings of the 11th European Conference on Computer Supported Cooperative Work, 7-11 September 2009, Vienna, Austria. Springer Verlag, London, pp. 243-262.

Birnholtz J.P., MJ Bietz (2003), Data at work: supporting sharing in science and engineering, Proceedings of the 2003 international ACM.

Freeman, J. (1972). The tyranny of structurelessness. Berkeley J. Sociol. 17, 151-164.

Groen, B., C. Hampden-Turner, (2005). The Titans of Saturn: Leadership and Performance Lessons from the Cassini - Huygens Mission. Cyan Books and Marshall Cavendish.

Lee, C. P., P. Dourish, G. Mark, (2006). ACM Press, http://portal.acm.org/citation.cfm?doid=1180875.1180950, p. 483.

Linde, C. (2001). Narrative and social tacit knowledge. J. Knowl. Manag. 5, 160-171.

Ribes, D., S. J. Jackson, (2013). in Raw data is an oxymoron, L. Gitelman, Ed. MIT Press, Cambridge MA, pp. 147-166.

Ribes, D., T. A. Finholt, (2007). in Proceedings of the 2007 international ACM conference on Conference on supporting group work - GROUP '07 ACM Press, Sanibel Island, Florida, USA; http://portal.acm.org/citation.cfm?doid=1316624.1316659, p. 229.

Rymer A.M. et al.(2020) Neptune-Odyssey Mission to the Neptune-Triton System: Planetary Mission Concept Study.

Sheehan, M., (2007). The International Politics of Space, Routledge, ed. 1.

Smith-Doerr, L, (2004). Women's Work: Gender Equality vs. Hierarchy in the Life Sciences Lynne Reinner Publishers, Boulder, CO.

Vertesi, J. (2020, in press). The Social Life of Spacecraft. The University of Chicago Press, Chicago.

Vertesi, J., P. Dourish, (2011). ACM Press, http://portal.acm.org/citation.cfm?doid=1958824.1958906, p. 533.

Weber, M. (1968). Economy and society; an outline of interpretive sociology. Edited by Guenther Roth and Claus Wittich. Translators: Ephraim Fischoff and others. Bedminster Press, New York, Wirtschaft und Gesellschaft. English. 